\title{
Clinopathological assessment of epulis lesions from Sindh Pakistan
} Arhama Surwaich $^{\text {a }}$, Surwaich Ali Channa ${ }^{b}$, Waqas Iqbal ${ }^{\mathrm{c}}$, Abdul Majid ${ }^{\mathrm{d}}$, Arsalan Ahmed ${ }^{\mathrm{e}}$, Fida Baloch ${ }^{\mathrm{f}}$ ${ }^{a}$ Assistant Professor, Department of Oral Pathology, Bhitai Medical College and Dental College Mirpurkhas. ${ }^{\mathrm{b}}$ Assistant Professor, Department of Oral Pathology, Bibi Aseefa Dental (SMBBMU) College Larkana.

'Associate Professor, Department of Oral Pathology, Isra Dental College, Isra University Hyderabad.

${ }^{\mathrm{d}}$ Associate Professor, Department of Pathology, Isra University Hyderabad.

${ }^{\mathrm{e}}$ Assistant Professor, Department of Periodontics, Avicenna Medical and Dental college lahore.

${ }_{\mathrm{f}}^{\mathrm{f}}$ Associate Professor, Department of Oral and Maxillofacial Surgery, Bhitai Dental and Medical College, Mirpurkhas. *Corresponding author: waqasiqbalhere@gmail.com

ABSTRACT

BACKGROUND \& OBJECTIVES: Gingival enlargement is a common characteristic of gums infection. Enlargement of the gums can possibly occur due to numerous factors, comprising of inflammatory disorders as well as certain meditational side effects. Pyogenic granuloma expresses as red, small erythematous papules on pedunculated or rather sessile base. The current study aims to evaluate the cases of epulis and to grade histological types of epulis.

METHODOLOGY: This descriptive cross-sectional study was carried out at oral surgery OPD ISRA Dental College for a six-month duration. The diagnosis of epulis was made on the basis of clinical and histological examination. The research data was recorded on pre-designed proforma, and data were analyzed using SPSS version 22.0 (IBM, Corporation).

RESULTS: Out of 150 study subjects, $90(60 \%)$ patients were female, while $60(40 \%)$ were male. Majority of the cases in our study were found with a maxillary site $(n=93,62.0 \%)$. Most had a size of $2 \mathrm{~cm}-3 \mathrm{~cm}(\mathrm{n}=132,76 \%)$. Coral Pink color was the most common in $(n=90,60 \%)$ patients, followed by red color $(n=45,30 \%)$ and pale color was found in $(n=15,10 \%)$ of the cases. The histological findings proved pyogenic granuloma was most common in $(n=75,50 \%)$ of the cases followed by fibrous epulis $(n=63,42 \%)$, peripheral giant cell granuloma $(n=6,4 \%)$ and Peripheral ossifying fibroma $(n=6,4 \%)$.

CONCLUSION: Pyogenic granulomas are the most prevalent reactive lesion. The lesions were more common in females in maxilla portion, and they were mostly found in the second to third decade of life.

KEYWORDS: Gingival disease, Pathology, Biopsy, Granuloma, Pyogenic.

\section{INTRODUCTION}

Oral mucosa is continuously dependent upon internal and external stimuli and thus manifests a range of disorders ranging from developmental, inflammatory, and reactive to neoplastic ${ }^{[1,2]}$. Most localized overgrowths of oral mucosa and gums are naturally considered as reactive instead of neoplastic. Clinically, these overgrowths frequently present problematic diagnostic situations as they imitate numerous pathologic activities groups. Clinically, these are alike, however, having unique histopathological characteristics [1,2].

Once the proliferation of connective tissues is restricted to gums, it represents epulides. It is described in a further suitable way as 'overgrowth on gums or chronic reactive hyper-genesis' ${ }^{[1-3]}$. They can possibly present as Pyogenic granuloma, Peripheral giant-cell granuloma, fibrous epulis, acrochordon, Peripheral ossifying fibroma, Giant cell fibroma, and Granuloma gravidarum. Numerous cases are undergoing these forms of epulis however a major difference lies between the above-mentioned forms ${ }^{[3]}$.
Previous histological research proposed that connective tissues respond to a variety of gums related irritations which ends up with hyper-genesis. It can possibly be caused by chronic irritation such as traumatic occlusion, calculus, or restoration and sometimes by hormonal conditions such as pregnancy and puberty ${ }^{[3,4]}$. The specific endocrine level contributes strongly resulting to such reactions.

Expert histopathologists affirmed that hyper-genesis led irritations can be seen microscopically at the tissue level causing severe harm to the patients ${ }^{[3,5]}$.

These lesions indicate the fact that different development stages reflect a different type of lesions, such as in the preliminary stages, such lesions are more of red color and sensitive enough to bleed even though by a slight touch and become quite firm with the passage of time, especially in the last stage it is more in shape like a leaf, mature and avascular ${ }^{[4,5]}$. Considering the histological perspective, a huge spectrum of changes is constantly varying, starting from the persistently, thick, and rich grind or crashed tissue to rather thickest avascular masses of clutter and noninflamed ones ${ }^{[4,5]}$. 
Pyogenic granuloma is often caused by the loss of interdental papilla. It appears to be a sessile mass with a smooth surface. It can possibly develop rapidly and remain for an indefinite period. It is vascular and tends to bleed easily as well as result in pain. It is generally present during pregnancy, so it is called Granuloma gravidarum $[6,7]$. On the other hand, Giant-cell fibroma represents large, darkly stained, and multinucleate cells. Clinically, PGCG rises from the gums or alveolar mucosa, and it appear as a red, nodular soft tissue mass. It is painless and causes pressure resorption of underlying alveolar bone ${ }^{[8-10]}$. Congenital epulis, also termed as, Congenital granular cell myoblastoma, granular cell fibroelastoma and Granular cell epulis of infancy. It is unclear why Congenital epulis takes place however, these are believed to instigate from primitive Mesenchymal cells of Neural crest origin ${ }^{[1]}$. It can be small and Pedunculated or either large and sessile, and mostly it is present on the gums. Epulis representing firm texture and slower pathogenesis generally called fibrous, whereas epulis dark in color with rapid progression is called myeloid. Similarly, further progression of myeloid results in ulceration and pain, leading to epithelioma formation. Babies are born generally with a protruding mass out of their mouth ${ }^{[11,12]}$. The histological evaluations suggest minimal recurrence chances of gum neoplasms. Whereas the clinical and microscopic assessments of oral mucosa are considered insufficient to manage potential lesions. There are frequent chances of dissemination of cancerous mucosal cells to oral cavity, breasts, lungs, colon, liver, and kidneys. Therefore, early histological examination is always required of the harmless clinical appearance ${ }^{[13]}$. Prior to complete removal of the defective fibrous lesions by surgical deletion, understanding site specific morphology of the aberrant tissue, therapeutic complications, and patient demographics are the key parameters of favorable therapy and histopathological diagnosis. This further minimizes the recurrence risk of the lesions. Therefore, the purpose of the study is to evaluate the relative incidence of different types of epulis isolated by localized biopsies of the oral cavity from the patients visiting Oral Surgery Department, Isra Dental College, Isra University Hyderabad, Sindh Pakistan. Previous studies conducted in India, Iran, and China focused mostly on some gingival swellings. However, the present study is the first study conducted in Sindh, Pakistan, to evaluate all gingival swellings presenting as epulis.

\section{METHODOLOGY}

We conducted a six-month (December 2016-June,2017) study at Oral Surgery Department, Isra Dental College, Isra University Hyderabad, Sindh Pakistan. The study was approved by the ethical board of studies via letter no. IU/ RR-10/AQK/BASR-24/2016/1306 and patient willingness to participate in the study was ensured by informed consent. All the patients clinically diagnosed with gingival outgrowth from all age groups and both genders were included. Patients taking epileptic drugs, immunosuppressants, and calcium channel blockers were excluded from the study. A provisional diagnosis of epulis was made on the basis of clinical examination.

After a careful history, relevant clinical features were recorded on proforma, and biopsies were conducted from a site. Biopsy procedure was performed locally, with infiltration near the lesion, or regionally, with a nerve block technique. Histopathological data was recorded on a predesigned proforma, and data was analyzed using SPSS version 22.0 (IBM, Corporation).

The tooth mobility assessment was done by using a digital approach intra-oral scanner measurement ${ }^{[13]}$. The continuous variables were presented as mean $\pm \mathrm{SD}$. Categorical variables were analyzed by Chi-square test, and Fisher's Exact test and results were presented as frequencies and percentages. Data was presented in tables, graphs, and charts.

\section{RESULTS}

Out of 150 study subjects, 90 (60\%) patients were female, while $60(40 \%)$ were male. The mean age of females was older as compared to male study subjects $(30.3 \pm 13.4$ vs $26.3 \pm 12$ years). Out of 150 patients, it was found that the majority of the cases were found with maxillary gingiva (anterior or posterior) i.e: ( $\mathrm{n}=93,62.0 \%)$.

The majority of the cases $(n=114,76 \%)$ were found with the lesion size range of $2 \mathrm{~cm}-3 \mathrm{~cm}$. Coral Pink color of the lesions was the most common in $(\mathrm{n}=90,60 \%)$ patients, followed by red color $(n=45,30 \%)$ and pale color was found in $(\mathrm{n}=15,10 \%)$ of the cases. Soft consistency was common in $(n=105,70 \%)$ while firm and hard were found in $(n=12$, $8 \%)$ and $(\mathrm{n}=33,22 \%)$ of the patients respectively. About 48 cases $(32 \%)$ were associated with tooth mobility, while 102 cases $(68 \%)$ were not associated with tooth mobility.

The histological findings proved pyogenic granuloma was most common in $(n=75,50 \%)$ of the cases followed by Fibrous epulis $(\mathrm{n}=63,41.33 \%)$, Peripheral giant cell granuloma $(n=6,4 \%)$, Peripheral ossifying fibroma $(n=7$, $4.66 \%$ ). While no case was reported of congenital epulis and pregnancy tumor. No significant difference was found in both genders according to histological evaluation by using Chi-Square test (p-value 0.16) as mentioned in TableIV.

Table-I: Age Distribution of patients $(n=150)$.

\begin{tabular}{ccc}
\hline Age Group & Frequency & Percentage \\
\hline Below 19 & $12(66.7 \%)$ & $15(65.2 \%)$ \\
$20-29$ & $6(33.3 \%)$ & $8(38.8 \%)$ \\
$30-39$ & $6(33.3 \%)$ & $15(65.2 \%)$ \\
$40-49$ & $12(66.7 \%)$ & $8(34.8 \%)$ \\
$50-59$ & $18(100 \%)$ & $8(34.8 \%)$ \\
$>60$ & - & $15(65.2 \%)$ \\
Gender & & \\
Male & 60 & $40 \%$ \\
Female & 90 & $60 \%$ \\
Total & 150 & $100 \%$ \\
\hline
\end{tabular}


Table-II: Frequency distribution of cases according to Site $(\mathbf{n}=\mathbf{1 5 0})$.

\begin{tabular}{ccccc}
\hline Site & $\begin{array}{c}\text { Gingiva } \\
\text { Anterior }\end{array}$ & $\begin{array}{c}\text { Gingiva } \\
\text { Posterior }\end{array}$ & Frequency & Percentage \\
\hline Maxilla & 75 & 18 & 93 & $62.0 \%$ \\
Mandible & 52 & 15 & 57 & $38.0 \%$ \\
\hline
\end{tabular}

Table-III: Frequency distribution of various cases variable.

\begin{tabular}{|c|c|c|}
\hline \multicolumn{3}{|c|}{ Frequency distribution of cases according to size $(n=150)$. } \\
\hline Size & Frequency & Percentage \\
\hline $2 \mathrm{~cm}-3 \mathrm{~cm}$ & 114 & $76 \%$ \\
\hline $2 \mathrm{~cm}-4 \mathrm{~cm}$ & 30 & $20 \%$ \\
\hline$>6 \mathrm{~cm}$ & 06 & $4 \%$ \\
\hline \multicolumn{3}{|c|}{ Frequency distribution of cases according to color $(n=150)$. } \\
\hline Color & Frequency & Percentage \\
\hline Coral pink & 90 & $60 \%$ \\
\hline Red & 45 & $30 \%$ \\
\hline Pale & 15 & $10 \%$ \\
\hline \multicolumn{3}{|c|}{ Frequency distribution of cases according to consistency $(n=150)$. } \\
\hline Firm & 12 & $8 \%$ \\
\hline Soft & 105 & $70 \%$ \\
\hline Hard & 33 & $22 \%$ \\
\hline \multicolumn{3}{|c|}{$\begin{array}{l}\text { Frequency distribution of lesions associated with tooth mobility ( } \mathrm{n}= \\
150) \text {. }\end{array}$} \\
\hline Yes & 48 & $32 \%$ \\
\hline No & 102 & $68 \%$ \\
\hline \multicolumn{3}{|c|}{$\begin{array}{l}\text { Frequency distribution of lesions according to histological diagnosis }(\mathrm{n}= \\
\text { 150). }\end{array}$} \\
\hline Fibrous epulis & 62 & $41.33 \%$ \\
\hline Pyogenic granuloma & 75 & $50 \%$ \\
\hline Peripheral Ossifying fibroma & 6 & $4 \%$ \\
\hline $\begin{array}{l}\text { Peripheral giant cell granu- } \\
\text { loma }\end{array}$ & 7 & $4.66 \%$ \\
\hline
\end{tabular}

Table-IV: Distribution of histological diagnosis according to gender $(n=150)$.

\begin{tabular}{ccccc}
\hline Epulis Type & \multicolumn{2}{c}{ Gender } & $\begin{array}{l}\text { Statistical } \\
\text { Test }\end{array}$ & p-value \\
\hline & $\begin{array}{c}\text { Male } \\
\mathbf{n}(\%)\end{array}$ & $\begin{array}{c}\text { Female } \\
\mathbf{n}(\%)\end{array}$ \\
\hline Fibrous epulis & $\begin{array}{c}20 \\
(13.33)\end{array}$ & $42(28)$ & $\begin{array}{c}\text { Chi-square } \\
\text { statistic is }\end{array}$ & $\mathrm{p}=0.160$ \\
Pyogenic granuloma & $33(20)$ & $42(28)$ & 1.9729 & \\
$\begin{array}{c}\text { Peripheral giant cell } \\
\text { granuloma }\end{array}$ & $4(2.67)$ & $3(2)$ & $\begin{array}{c}\text { Fisher exact } \\
\text { test statistic } \\
\text { value is }=1\end{array}$ & $\mathrm{p}<0.125$ \\
\hline $\begin{array}{c}\text { Peripheral ossifying } \\
\text { fi-broma }\end{array}$ & $3(2)$ & $3(2)$ & & \\
\hline
\end{tabular}

\section{DISCUSSION}

Previous research reports led by expert histopathologists, recognized epulis as a benign lesion of the oral cavity located over the gingiva ${ }^{[14,15]}$.
Our study extends histopathological understandings of epulis by measuring the exact range of gingival swelling ranging $2 \mathrm{~cm}$ up to $6 \mathrm{~cm}$ among 150 cases.

This was the first study conducted in the Sindh region of Pakistan, focusing on 150 patients suffering from gingival swelling (epulis). We found a significant rise in gingival swellings among Sindhi adults. A recent study led by Azodo $\mathrm{R}$ et al, unveiled similar findings that increased size gingival swelling was found common among adults. In contrast to this another study led by Chalkoo $\mathrm{AH}$ et al., reported $37 \%$ of gingival swellings among patients from 31-45 years of age range. The major reasons may include little knowledge of periodontal care, hormonal imbalance, and stress ${ }^{[16-18]}$. In our study female were in the majority i.e $(60 \%)$, while 60 $(40 \%)$ were male. However, inconsistent results were found in the study of Jalayer Naderi et al, who reported a higher prevalence of these lesions in men. The possible reason for this deviation may include factors of social well-being and poor educational status, and lack of awareness regarding periodontal care among patients from Sindh, Pakistan.

We found $93(62.0 \%)$ suffering from maxillary gingival swelling. Another study led by Carod-Artal et al also found maxillary gingival swelling among most epulis cases ${ }^{[19,20]}$. Chi-square test was applied for both fibrous epulis and pyogenic granuloma, and non-significant gender association was noted ( $p$-value $=0.160$ ) as mentioned in Table-IV. Our findings are consistent with the previous study reported by Chalkoo AH et al, ${ }^{[16]}$, who observed pyogenic granuloma and other lesions most common among females. However, our findings are inconsistent with the previous study reported by Ramu S et al, who observed pyogenic granulomas and fibrous epulis the most common lesions affecting males. Similarly, we applied fisher exact test where the variable values were less than 5 and the value of 1 against fisher testing represents non-significant $(p=0.125)$ gender association focusing on Peripheral giant cell granuloma and Peripheral ossifying fibroma (Table-III) ${ }^{[20-24]}$. Our findings reveal that the lack of knowledge and awareness regarding periodontal care are the key factors of epulis progression.

LIMITATIONS: The study was limited to Sindhi patients with gingival swelling, size ranging from 2-6 cm, epulis consistency, color, and motility related parameters patients from all age groups and both genders.

\section{CONCLUSION}

It is concluded that clinically most lesions presenting as epulis were painless, soft, coral pink in color, around 2-6 $\mathrm{cm}$ in diameter, and sessile in nature. Pyogenic granuloma was the most prevalent subtype of epulis, unveiling nonsignificant gender association rejecting the null hypothesis.

ACKNOWLEDGEMENT:I acknowledge the contributions of my co-authors for supporting in patient selection, clinical assessment, and in data analysis. Secondly, I also extend thanks to reviewers for language check and recommending potential additions for making this manuscript worth sharing. 
GRANT SUPPORT \& FINANCIAL DISCLOSURE: The presented manuscript was extracted from Dr. Arhama Surwaich master's degree thesis in oral Pathology.

CONFLICT OF INTEREST: None.

\section{REFERENCES}

1. Lakkam BD, Astekar M, Alam S, Sapra G, Agarwal A, Agarwal AM. Relative frequency of oral focal reactive overgrowths: An institutional retrospective study. Journal of Oral and Maxillofacial Pathology. 2020;24(1):70-80. Doi: 10.4103/jomfp.JOMFP_350_19

2. Ayaz M, AFZAL S, Mehdi H, Kaukab H. Prevalence of reactive hyperplastic oral lesions. Pakistan Oral \& Dental Journal. 2020;40(3):162-166.

3. Aloua R, El Bouihi R, Slimani F. Giant Mandibular Epulis: A Case Report. International Journal of Research and Reports in Dentistry. 2020:29-32.

4. Martins-Chaves RR, Guimarães LM, Pereira TD, Pereira NB, Chrcanovic BR, Fonseca FP, et al. KRAS mutations in implant-associated peripheral giant cell granuloma. Oral Diseases. 2020;26(2):334-340.

5. LonePA,AhmedT,AhmedT,KumarV.Clinicopathologic features of central \& peripheral giant cell lesions of oral cavity: Our clinical experience. International Journal of Applied Research. 2016;2(10):29-33.

6. Gandhi B, Dhuvad J, Johnson A, Bhavsar D. Reactive lesions of oral cavity. National Journal of Integrated Research Medicine. 2016;7(4):154-157.

7. Sharma S, Chandra S, Gupta S, Srivastava S. Heterogeneous conceptualization of etiopathogenesis: Oral pyogenic granuloma. National Journal of Maxillofacial Surgery. 2019;10(1):3-7. Doi: 10.4103/ njms.NJMS 5518

8. Pardeshi KV, Mirchandani NM, Agrawal AA, Kale TM. Fibrous hyperplasia: Two case Reports. Journal of Dental Lasers. 2016;10(1):23-27. Doi: 10.4103/09762868.184604

9. Da Silva Barros CC, De Souto Medeiros MR, De Azevedo RA, Da Costa Miguel MC, Dos Santos JN, Da Silveira ÉJ. Peripheral dentinogenic ghost cell tumorreport of two cases and review of the literature. Oral and Maxillofacial Surgery. 2021:1-5. Doi:10.1007/s10006021-00947-x

10. Maheshwari S, Bhutada G, Palve DB. Peripheral giant cell granuloma-a review and case report. International Journal of Healthcare and Biomedical Research. 2017;5(2):53-58.

11. Bang KO, Bodhade AS, Dive AM. Congenital granular epulis of a new born. Dent Research Journal (Isfahan). 2012; 9 (Suppl 1): S136-S138.

12. Sah BK, Koirala B, Dali M, Shrestha S. Peripheral Ossifying Fibroma: A Case Report. Journal of Nepalese Society of Periodontology and Oral Implantology. 2020;4(1):39-42.

13. Meirelles L, Siqueira R, Garaicoa-Pazmino C, Yu SH, Chan HL, Wang HL. Quantitative tooth mobility evaluation based on intraoral scanner measurements. Journal of Periodontology. 2020;91(2):202-208. Doi:10.1002/JPER.19-0282
14. Anisuzzaman MM, Alam MK, Khan SR, Kamrujjaman M. Giant Fibrous Epulis in the Posterior Segment of Mandible: A Clinical Note. International Medical Journal. 2019;26(3):241-242.

15. Azodo CC, Erhabor P. Discrete gingival enlargement resulting from artificially created maxillary midline diastema. Journal of Clinical Sciences. 2017;14(1):4952. Doi: 10.4103/2468-6859.199165

16. Chalkoo AH, Ahmad MB. Localized benign lesions of oral cavity: A clinicopathological study of 95 cases: A retrospective analysis. 2012-2014. Pakistan Oral \& Dental Journal. 2015;35(2).

17. Akazane, A. and Hassam,B. Images in Medicine. Epulis: à propos d'un cas. Pan African Medical Journal. 2014; 17.

18. Carod-Artal FJ. 10 Infections of the Spinal Cord. CNS Infections: A Clinical Approach. 2018:199.

19. Boza Oreamuno YV, López Soto A. Retrospective analysis of oral mucosal lesions between 2008-2015 in the clinical boarding school of dentistry of the University of Costa Rica. Población y Salud en Mesoamérica. 2019;16(2):134-154. Doi:10.15517/psm.v0i0.34404

20. Rajanikanth BR, Moogla S, Suragimath G, Pai BJ, Walvekar A, Kumar R. Localized gingival enlargement a diagnostic dilemma. Indian Journal of Dentistry. 2012;3(1):44-48. Doi: 10.1016/S0975962X(12)60013-6

21. Kadeh H, Saravani S, Tajik M. Reactive hyperplastic lesions of the oral cavity. Iranian Journal of Otorhinolaryngology. 2015;27(79):137-144.

22. Handanakere SS. Clinical study of benign tumours and tumour like lesions of oral cavity. IP Journal of Otorhinolaryngology and Allied Science. 2020;3(3):104-108.

23. Silva MF, Barbosa KG, Pereira JV, Bento PM, Godoy GP, Gomes Prevalence of oral mucosal lesions among patients with diabetes mellitus types 1 and 2. Anais Brasileiros De Dermatologia. 2015;90(1):49-53. Doi:10.1590/abd1806-4841.20153089

24. Ramu S, Rodrigues C. Reactive hyperplastic lesions of the gingiva: a retrospective study of 260 cases. World Journal of Dentistry. 2012;3(2):126-130.

Author's Contribution:

Arhama Surwaich: Data Acquisition and histopathological evaluations.

Surwaich Ali Channa: Data Analysis and histopathological evaluations.

Waqas Iqbal: Patient selection, clinical evaluations, and data correlation.

Abdul Majid:

Arsalan Ahmed: Data collection and determination of the data.

Fida Baloch: Patient selection and approval.

Submitted for Publication:23-03-2021

Accepted after revision: 22-10-2021 